\section{Myo-inositol influences Release and Inactivation of Murine Sarcoma Virus from Desiccated Transformed Mouse Embryo Cells}

IT has been reported ${ }^{1-3}$ that certain viruses, including Rous sarcoma virus (RSV) and murine leukaemia viruses (MLV), can be released in highly infectious form from host cells dried in the presence of myo-inositol at certain relative humidities; and the structural importance of bound water and its replacement by myo-inositol in biological systems has been reviewed recently ${ }^{4}$.

The advent of a reliable in vitro assay system for MSV (Moloney) $^{5}$ (a murine sarcoma virus) $)^{6}$ has allowed us to investigate the influence of partial desiccation and inositol on virus released from MSV (Moloney) transformed cells. Cultures of transformed mouse embryo cells in $60 \mathrm{~mm}$ plastic Petri dishes were treated for $2 \mathrm{~h}$ at $37^{\circ} \mathrm{C}$ with either $4 \mathrm{ml}$. growth medium $(199+5$ per cent calf serum) or a $1: 1$ mixture of growth medium plus 5 per cent myo-inositol in water (isotonic). After removal of these media the open plates were dried in a humidifier pre-set at various relative humidities. Pairs of plates were removed at different time intervals, the dried cells scraped into $1.0 \mathrm{ml}$. of fresh growth medium, and the cell debris deposited at $1,000 \mathrm{~g}$. The supernatant was assayed on 15 day old Swiss mouse embryo cells ${ }^{5}$. Virus released from parallel cultures frozen and thawed three times was assayed to establish an arbitrary 100 per cent yield for reference.

Each curve in Fig. 1 incorporates the results of at least three experiments. Clearly two phenomena are represented: $(a)$ virus released from the drying cells, and $(b)$ the decay of infectivity (and transforming ability) of the released virus.

Desiccation results in larger virus yields from the transformed cells at all relative humidities with the possible exception of untreated cells at 30 per cent relative humidity. Here, rapid inactivation may mask any increase in yield. After 3-5 min drying no further increase in virus yield occurs and the remainder of the curve chiefly represents the decay rates of the virus. In all cases inositol protected virus against inactivation with maximum protection occurring at 30 per cent relative humidity. This is in general agreement with results obtained during the desiccation of $\mathbf{R S V}^{2}$.

MSV is known to be unstable to repeated freezing and thawing, and the increased virus yields during the first

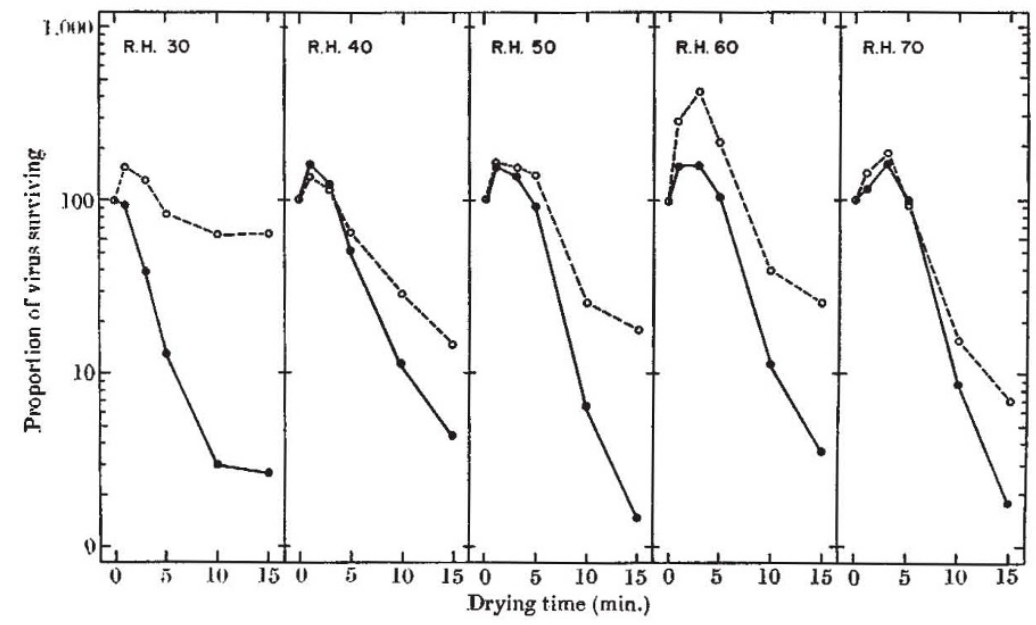

Fig. 1. Release and decay of MSV (Moloney) from infected mouse embryo cells dried at different relative humidities. Solid lines represent virus released from controls held for $2 \mathrm{~h}$ in growth medium before drying. Broken lines represent virus released from cells held for $2 \mathrm{~h}$ in a 1:1 mixture of growth medium and 5 per cent myo-inositol before drying. Each curve represents at least three sets of experiments. few minutes of drying suggest that this may be a hetter method of obtaining virus. The higher yield at 60 per cent relative humidity in the presence of inositol (two to three times greater than controls) may be because loss of bound water over the critical range 55-75 per cent relative humidity results in considerable distortion of DNA and marked changes in biological integrity which can be prevented by inositol ${ }^{7,8}$. All evidence so far indicates that MSV contains an RNA genome ${ }^{9-12}$ but the response to drying of both MSV and $\mathrm{RSV}^{1,2}$ suggests that the role of bound water in maintaining the integrity of RNA is similar to its role in DNA viruses.

University of Saskatchewan,

R. BATHER

J. YANG

Saskatoon, Canada.

Received June 24, 1968; revised March 18, 1969.

${ }^{1}$ Webb, S. J., Bather, R., and Hodges, R. W., Canad. J. Microbiol., 9, 87 (1963).

${ }^{2}$ Webb, S. J., Cook, C. A. M., and Bather, R., Canad. J. Biochem., 42, 157 (1964).

${ }^{3}$ Bather, R., Webb, S. J., and Cunningham, T. A., Nature, 207, 30 (1965).

Webb, S. J., Bound Water in Biological Integrity (C. C. Thomas, Springfield, Illinois, 1965).

Bather, R., Leonard, A., and Yang, J., J. Nat. Cancer Inst,

? Falk, M., Hartman, K. A., and Lord, R. C., J. Amer. Chem. Soc., 85, 387 (1963).

'Webb, S. J., and Bhorjee, J. S., Canad. J. Microbiol., 46, 691 (1968).

'Buck, B. M., and Bather, R., J. Gen. Virology (in the press).

${ }^{10}$ Duesberg, P. H., and Robinson, W. S., Proc. US Nat. Acad. Sci., 55, 219 (1966).

Shibley, G. P., Durr, F. E., Schidlovski, G., Wright, B. S., and Schmitter, R., Science, 156, 1610 (1967).

12 Nakata, Y., and Bader, J. P., J. Virology, 2, 1255 (1968).

\section{Replication of Cat Leukaemia Virus in Cell Suspension Cultures}

LEUKaemia (lymphosarcoma) virus (FLV) has been detected in cat tissue and plasma ${ }^{1-3}$. The "C"-type virus, in addition to replicating from plasma and vacuolar membranes of a variety of cell types, is also morphologically similar to murine leukaemia viruses ${ }^{4}$. While studying in vitro bovine leukaemia our group established a successful method for propagation of lymphoid cell suspension cultures $^{5}$. These lymphoid cells had a hyperdiploid chromosome complement and they were devoid of recognizable virus. Because tissue from cats with leukaemia contains "C"-type virus, we have tested to see if cells grown in suspension cultures derived from such tissue continue to replicate leukaemia virus in culture. We now report the development of a successful method for propagation of "C"-type FLV in lymphoid cells grown continuously in cell suspension, which should provide a standard and constant source of FLV.

Methods for detection of virus and preparation of inocula for the first transmission experiment have been reported ${ }^{3}$. Virus was concentrated from tissue of a 3 year old cat with spontaneous leukaemia by differential centrifugation. Two and three-tenths (2.3) g equivalents were inoculated intraperitoneally into five 1 day old kittens. Three developed leukaemia, confirmed by histology, within 8 weeks. Virus was concentrated from tissue of two of these kittens using the same technique. Two and fivetenths $(2 \cdot 5) \mathrm{g}$ equivalents were inoculated intraperitoneally into four 1 day old kittens in a second cell-free passage of the virus in cats. The latent period was longer in the second transmission experiment. Two of 